\title{
The role of HFE genotype in macrophage phenotype
}

\author{
Anne M. Nixon ${ }^{1 *}\left(\mathbb{D}\right.$, Elizabeth Neely', Ian A. Simpson ${ }^{2}$ and James R. Connor ${ }^{1}$
}

\begin{abstract}
Background: Iron regulation is essential for cellular energy production. Loss of cellular iron homeostasis has critical implications for both normal function and disease progression. The H63D variant of the HFE gene is the most common gene variant in Caucasians. The resulting mutant protein alters cellular iron homeostasis and is associated with a number of neurological diseases and cancer. In the brain, microglial and infiltrating macrophages are critical to maintaining iron homeostasis and modulating inflammation associated with the pathogenic process in multiple diseases. This study addresses whether HFE genotype affects macrophage function and the implications of these findings for disease processes.

Methods: Bone marrow macrophages were isolated from wildtype and H67D HFE knock-in mice. The H67D gene variant in mice is the human equivalent of the H63D variant. Upon differentiation, the macrophages were used to analyze iron regulatory proteins, cellular iron release, migration, phagocytosis, and cytokine expression.

Results: The results of this study demonstrate that the H67D HFE genotype significantly impacts a number of critical macrophage functions. Specifically, fundamental activities such as proliferation in response to iron exposure, L-ferritin expression in response to iron loading, secretion of BMP6 and cytokines, and migration and phagocytic activity were all found to be impacted by genotype. Furthermore, we demonstrated that exposure to apo-Tf (iron-poor transferrin) can increase the release of iron from macrophages. In normal conditions, $70 \%$ of circulating transferrin is unsaturated. Therefore, the ability of apo-Tf to induce iron release could be a major regulatory mechanism for iron release from macrophages.
\end{abstract}

Conclusions: These studies demonstrate that the HFE genotype impacts fundamental components of macrophage phenotype that could alter their role in degenerative and reparative processes in neurodegenerative disorders.

Keywords: Iron, Macrophages, Microglia, HFE, H63D, H67D, Inflammation

\section{Background}

Iron is a critical cofactor in many biological and physiological processes [1]. Therefore, iron mismanagement can lead to dysfunction and damage to multiple systems. In recent years, particular interest has been developed in the HFE (high iron) gene. The HFE gene encodes the HFE protein, a transmembrane glycoprotein similar to the major histocompatibility complex (MHC) molecules [2]. HFE contributes to the regulation of iron through its ability to bind to transferrin receptors on cellular membranes $[3,4]$. There are three known polymorphisms of the HFE gene: H63D, C282Y, and S56C. The

\footnotetext{
* Correspondence: anixon0610@gmail.com

${ }^{1}$ Department of Neurosurgery, The Pennsylvania State University College of

Medicine, M.S. Hershey Medical Center, Hershey, PA 17033, USA

Full list of author information is available at the end of the article
}

C282Y variant is only present in $<2 \%$ of the population but is found in $90-95 \%$ of hemochromatosis patients [2, 5-8]. The H63D variant is the most common gene variant in Caucasians being reported in as high as $15-20 \%$ of the population $[5,8]$. Our interest in the H63D HFE variant began with studies by our group and others reporting that this gene variant is increased in neurodegenerative diseases such as Alzheimer's disease (AD) and amyotrophic lateral sclerosis (ALS) [9-11]. When mice with the H67D HFE gene variant (mouse homolog of H63D) are bred with the SOD1 mutant mouse model of ALS the result is accelerated disease progression [12]. These double transgenic mice have increased staining for microglia suggesting greater activation of microglia could contribute to the accelerated 
disease process. With normal aging, the H67D mice have an increase in ferritin expression in the brain which is associated with increased microglial staining profile $[13,14]$.

One of the key phenotypes associated with the HFE gene variant is that reticuloendothelial cells, specifically macrophages, are iron-poor $[15,16]$. Macrophages normally play an important role in iron homeostasis through phagocytosis of debris and recycling iron [1720]. Therefore, altered iron handling by macrophages and brain microglia could be part of the mechanism by which the H63D HFE variant may impact disease states. Iron status and microglial function have been demonstrated by a number of studies. The evidence is compelling that decreasing iron results in decreasing proinflammatory activity [21-23], whereas increasing iron results in increased pro-inflammation [24, 25] and decreased microglial phagocytic activity [24]. The HFE genotype status can be expected then to alter macrophage and microglia phenotype because the mutated HFE protein reportedly limits iron uptake in macrophages $[26,27]$. In the brain, microglia are the resident macrophage and play a critical role in neurodegenerative diseases [28]. For example, both iron accumulation and increase in microglia and infiltrating macrophages occur in the brain with age which is thought to underlie the agerelated increase in neuroinflammation and production of free radicals in the brain [29]. Our laboratory has been focused on the role of iron in neurodegenerative disease and normal brain function. In this study, we use macrophages as a model for interrogating the HFE genotype impact. Despite microglia and macrophage structural differences, they share important biological functions, such as iron loading with activation [30,31], mediating inflammation, and recruitment of monocytes [32]. Microglia and infiltrating macrophages have a key role in neurodegenerative diseases, such as AD, multiple sclerosis, ALS, and spinal cord injury. For example, macrophages have been shown to be more efficient at clearing $A \beta$ plaque than microglia [33], accumulate excess iron upon activation of TLR4 within iron overload sites of CNS injury [34], and migrate from the periphery to CNS where they may cause increased inflammation or relapse in MS patients [35].

Lastly, the HFE genotype is linked to increased frequency of cancer and macrophages are known to infiltrate brain tumors as important contributors to the tumor microenvironment [36-39]. Thus, HFE mediated iron regulation in macrophages and microglia, and its relationship to inflammatory responses may provide a mechanistic link between otherwise unrelated diseases.

\section{Methods}

\section{Mouse colony}

C57BL/6 J $\times 129$ mice (12-month-old males) were utilized for this study. As previously described, the mice expressed either wildtype (WT) or the H67D HFE gene variant, the latter is a homolog for the human H63D HFE mutation [40]. The mice were maintained, inhouse, in an animal facility at The Pennsylvania State University, College of Medicine. All procedures were approved by the Pennsylvania State University, College of Medicine, Institutional Animal Care and Use Committee, Protocol 04-166.

\section{Primary macrophage culture}

Bone marrow-derived cells were extracted and cultured, as previously described [41]. Briefly, the mice were sacrificed by cervical dislocation and the femurs and tibias were removed, and epiphyses excised. The bone marrow was then flushed using Dulbecco's phosphatebuffered saline (DPBS) (Corning; Manassas, VA). The resulting cell suspension was passed through a $40-\mu \mathrm{m}$ cell strainer. The bone marrow cells were then plated in $100-\mathrm{mm}^{2}$ tissue culture plates at a concentration of $8 \times 10^{6}$ cells/plate. The cells were maintained in Dulbecco's Modified Eagle's Medium (DMEM) (Invitrogen; Grand Island, NY) with 10\% fetal bovine serum (FBS) (Gemini Bio Products; West Sacramento, CA), 1\% penicillin-streptomycin (Invitrogen; Grand Island, NY), and $10 \mathrm{ng} / \mathrm{ml}$ macrophage colony stimulating factor (M-CSF) (R\&D Systems; Minneapolis, $\mathrm{MN}$ ); and incubated at $37{ }^{\circ} \mathrm{C}$ under an atmosphere of $5 \% \mathrm{CO}_{2}$ with humidified air. M-CSF was added to the cell culture media to allow differentiation of the bone marrow cells to bone marrow-derived macrophages (BMMs). Verification of bone marrow macrophage differentiation was confirmed through flow cytometry using macrophage surface and intracellular markers F4/80, CD11b, and CD68, as previously described [41]. Briefly, differentiated macrophages $\left(1.2 \times 10^{7}\right.$ cells/sample) were resuspended in DPBS. Fc receptor blocking antibody (eBioscience; San Diego, CA) was added to each cell sample to prevent nonspecific antibody staining. Subsequently, anti-F4/80-FITC (BioLegend; San Diego, CA) and anti-CD11b-APC (BioLegend; San Diego, CA) were separately added to two of the cell suspensions and incubated at $4^{\circ} \mathrm{C}$, in the dark for $30 \mathrm{~min}$ to prevent photobleaching. All cell samples were resuspended in BD Cytofix/Cytoperm reagent (BD Biosciences; San Jose, CA) and incubated for $20 \mathrm{~min}$ in the dark at $4{ }^{\circ} \mathrm{C}$. The cell samples were then washed and resuspended with BD Perm/Wash buffer (BD Biosciences; San Jose, CA). Anti-CD68-PE (BioLegend; San Diego, CA) was then added to an unstained cell sample, and incubated for $30 \mathrm{~min}$ at $4{ }^{\circ} \mathrm{C}$, in the dark for $30 \mathrm{~min}$. Lastly, the cell samples were washed and subjected to flow cytometry using BD FACSCalibur (BD Biosciences; San Jose, CA). The resulting data were analyzed using FlowJo 
software in which fluorescence intensity of macrophagespecific markers were compared to the fluorescence intensity of unstained control cells.

\section{MTT and LDH assays}

To determine the viability of the macrophages, 3-(4,5-dimethylthiazol-2-Yl)-2,5-diphenyltetrazolium Bromide (MTT) and lactate dehydrogenase (LDH) were used. Following differentiation, the macrophage cultures were washed with DPBS and divided into three different groups: (1) control media (same as culture media), (2) media supplemented with $300 \mu \mathrm{M}$ ferric ammonia citrate (FAC) (Sigma Aldrich; St. Louis, MO) for iron loading, or (3) media supplemented with $300 \mu \mathrm{m}$ deferoxamine (DFO) (Sigma Aldrich; St. Louis, MO), an iron chelator. Following a 24-h incubation period, the cells were washed with DPBS. The media in all groups was then replaced with control media and the cells incubated for an additional 24-h. Subsequently, cell viability was assessed using MTT (Roche; Basal, Switzerland) and LDH (Roche; Basal, Switzerland) assays, according to manufacturer's instructions. Fluorescence was measured on a SpectraMax Gemini EM plate reader (Molecular Devices; Sunnyvale, CA).

\section{Enzyme linked Immunosorbent assays (ELISAs)}

The macrophages were cultured and treated as described above. Following differentiation, the macrophages were lysed in RIPA buffer, (Sigma Aldrich; St. Louis, MO) that included a 1:100 dilution of protease inhibitors (Sigma Aldrich; St. Louis, MO). Protein concentrations were determined using a BCA protein assay kit (Pierce; Rockford, IL).

\section{Iron proteins}

The cell lysates were used to measure the amount of iron proteins in wildtype and H67D macrophages. We performed enzyme-linked immunosorbent assays (ELISAs) for the iron proteins: L-ferritin (Abcam; Cambridge, UK), H-ferritin (Mybiosource; San Diego, CA), transferrin receptor (BlueGene; Shanghai, China), and ferroportin (Cloud-Clone Corp; Houston, TX), according to their manufacturer's instructions. Absorbance of the cell lysates was measured using a SpectraMax 340PC plate reader (Molecular Devices; Sunnyvale, CA).

\section{Bone morphogenetic protein 6 (BMP6) and bone morphogenetic type I receptor (ALK3)}

To quantify the amount of BMP6 and ALK3 within the macrophages, the cells were harvested and lysed as described previously. In addition, the amount of BMP6 secreted from the macrophages was determined from the media collected at the time of cell harvest. The samples were analyzed with a BMP6 (DL Develop; Wuxi, Jiangsu, China) or ALK3 (Mybiosource; San Diego, CA) specific ELISA according to manufacturer's instructions. The absorbance of the cell lysates and cell culture media was measured on a SpectraMax 340PC plate reader, (Molecular Devices; Sunnyvale, CA).

\section{Phagocytosis assay}

For the phagocytosis assay, $1 \times 10^{4}$ macrophages/wells were plated on a black bottom 96-well plate. The cells were incubated with cell culture media for 24-h and then the media was replaced with fluorescently labeled E. coli bioparticles (Molecular Probes; Eugene, OR) for an additional $2 \mathrm{~h}$. Subsequently, the bioparticles were aspirated and excess fluorescence was quenched with trypan blue. The remaining fluorescence of the cells was measured on a SpectraMax Gemini EM plate reader (Molecular Devices; Sunnyvale, CA), at $480 \mathrm{~nm} / 520 \mathrm{~nm}$.

\section{Cellular migration}

Cellular migration of macrophages was assessed using a Cytoselect Cell Invasion Assay (Cell Bio Labs, Inc.; San Diego, CA), consisting of a 5-um membrane insert. One million macrophages in serum-free media were added to the membrane insert. The lower well of the migration plate contained FBS supplemented cell culture media. The cell suspension was incubated for $24 \mathrm{~h}$ at $37{ }^{\circ} \mathrm{C}$. Following incubation, the cells that had migrated into the lower well were lysed, using a fluorescent lysis buffer. Fluorescence of the macrophages was measured on a SpectraMax Gemini EM plate reader (Molecular Devices; Sunnyvale, CA), at $480 \mathrm{~nm} / 520 \mathrm{~nm}$.

\section{Cytokines analysis}

Cytokine levels from macrophage cell lysates were assessed using a mouse cytokine array kit (R\&D Systems; Minneapolis, MN). The macrophages were incubated with either control media, $50 \mathrm{ng} / \mathrm{ml}$ of lipopolysaccharide (LPS) (Sigma Aldrich; St. Louis, MO), or $100 \mathrm{uM}$ paraquat dichloride hydrate (Sigma Aldrich; St. Louis, MO) for 24-h. Dosages were selected based on previous reports [42, 43]. Following incubation, the cells were washed with PBS and lysed with the assay lysis buffer. The lysates were then mixed with a cocktail of biotinylated antibodies and incubated on a nitrocellulose membrane containing 40 different cytokine antibodies. Next, the membranes were washed and incubated with streptavidin-HRP for $30 \mathrm{~min}$ and then developed following the manufacturer's instructions using GE Amersham Imager 600 (GE; Buckinghamshire, UK). The blots were analyzed using ImageJ software (NIH; Bethesda, MD).

\section{${ }^{59} \mathrm{Fe}$ loading and release}

To determine iron release, macrophages were loaded with ${ }^{59} \mathrm{Fe}$ and the amount of iron released was monitored by sampling the media over 24-h. One million 
macrophages were plated in a 6-well tissue plate and incubated with $2 \mu \mathrm{Ci} /$ well of ${ }^{59} \mathrm{Fe}-\mathrm{NTA}$ complex overnight. The ${ }^{59} \mathrm{Fe}-\mathrm{NTA}$ complex was generated, as previously described [44]. After iron loading, the cells were washed twice with DPBS to remove iron from the culture media. The media was then replaced with fresh media containing either control, control $/ 500 \mathrm{nM}$ hepcidin, $50 \mathrm{mg} / \mathrm{ml}$ apo-transferrin(apo-Tf), apo-Tf/hepcidin, $20 \mu \mathrm{M}$ DFO, or DFO/hepcidin media. Aliquots of the media $(100 \mu \mathrm{l})$ were collected at $0,4,8,12$, and 24-h. The amount of ${ }^{59} \mathrm{Fe}$ within the collected samples was measured on a Beckman Gamma 4000 (Beckman Coulter; Brea, CA).

\section{Statistical analysis}

Macrophage cultures were obtained from cells isolated from three different animals. One set of macrophage cultures was established for each animal; each set consisting of triplicate plating of macrophages. Each experiment was repeated three times on each set of cultures. Statistical analyses were performed using the GraphPad Prism (La Jolla, CA). The results are presented as mean \pm SEM. Statistical comparisons were made using an ungrouped $t$ test or a one-way analysis of variance (ANOVA) as appropriate. A $p$ value of $\leq 0.05$ was considered statistically significant.

\section{Results}

Increased cell proliferation of wildtype macrophages with iron exposure

Wildtype macrophages treated with $300 \mu \mathrm{M}$ FAC had a $24 \%$ increase $(p<0.0001)$ in cellular proliferation compared to the non-iron-treated WT group. The addition of iron had no effect on the proliferation of the H67D HFE macrophages. Treatment with the iron chelator DFO had no effect on cell viability of either genotype (Fig. 1a). The manipulation of iron content had no effect on LDH release for either group (Fig. 1b).

\section{Iron loading induces greater L-ferritin expression in H67D HFE macrophages}

To interrogate intracellular iron handling, we assessed the expression of several key iron regulatory proteins following exposure to iron or an iron chelator. Specifically, we assessed the expression of L-ferritin, $\mathrm{H}$-ferritin, transferrin receptor, and ferroportin in the macrophage lysates. Macrophages were incubated with control, $300 \mu \mathrm{M}$ FAC or $300 \mu \mathrm{M}$ DFO media. L-ferritin expression was significantly $(p<0.0001)$ increased following exposure to iron in both WT and H67D macrophages; however, there was $2 \times$ the amount of L-ferritin in the H67D cells compared to WT (Fig. 2a; $p<0.0001$ ) following iron loading. DFO exposure had no effect on L-ferritin expression in macrophages for either genotype (Fig. 2a). The $\mathrm{H}$-ferritin subunit expression was not affected in either genotype by any of the iron manipulations (Fig. $2 b)$. Ferroportin was detected in untreated control macrophages at the same level across genotypes. In response to iron treatment, both WT and H67D macrophages had similar increases in expression of ferroportin. Exposure to the iron chelator, DFO, had no effect on expression of ferroportin (Fig. 2c). Lastly, high levels of the transferrin receptor were detected in both genotypes and these levels were unchanged by iron loading or iron chelation (Fig. 2d).
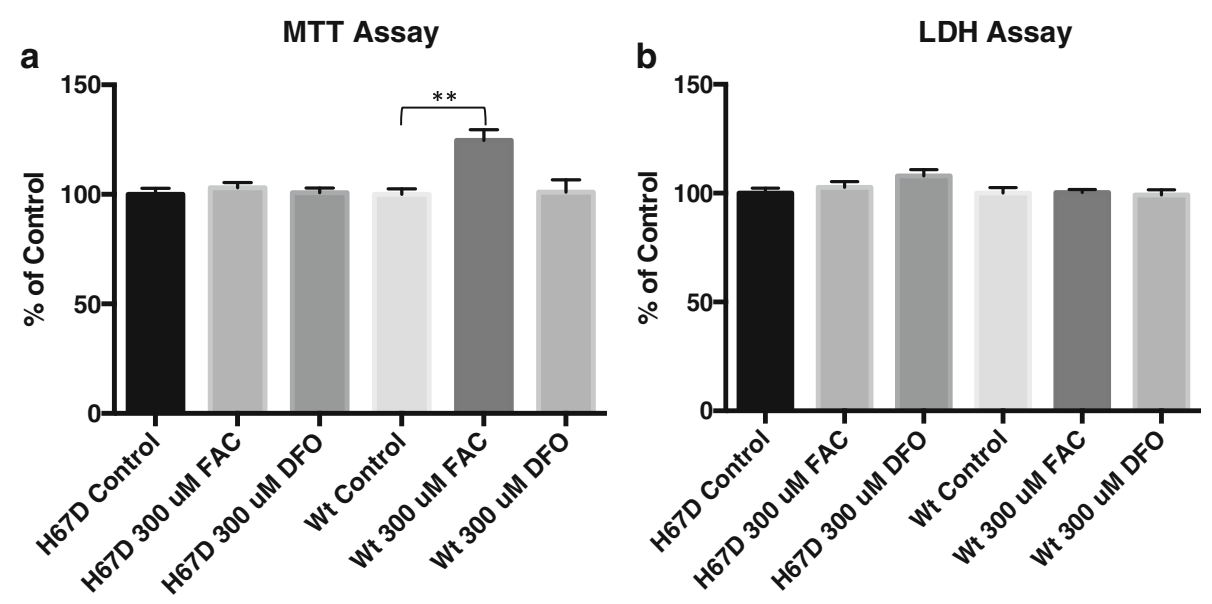

Fig. 1 Cell proliferation (MTT) and cytotoxicity (LDH) of macrophages following iron loading and iron chelation. MTT (a) and LDH (b) assays were carried out to determine cell proliferation and cellular toxicity, respectively. The cells were exposed to control, 300 uM FAC, or $300 \mu M$ DFO supplemented media for $24 \mathrm{~h}$. Subsequently, the media was replaced with control media for an additional $24 \mathrm{~h}$, and cell proliferation/cytotoxicity was assessed. Data represent the mean \pm SEM from three independent experiments performed with triplicate samples and are compared to all treatment groups for statistical significance using one-way ANOVA. ${ }^{*}$ Compared to control $p<0.01$ 


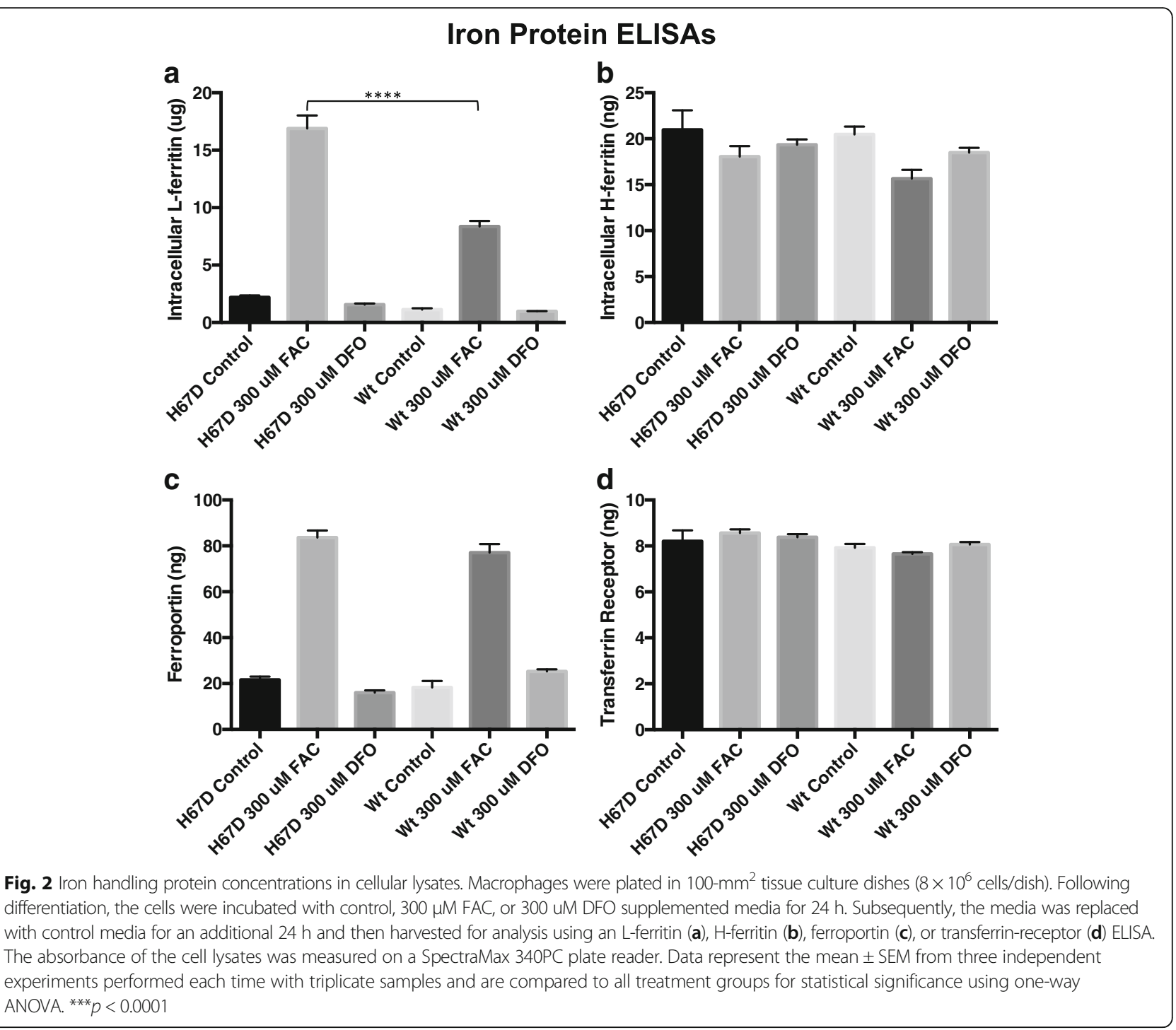

H67D HFE is associated with increased BMP6 secretion The expression of BMP6 and its receptor ALK3 were assessed in H67D HFE and WT macrophages. BMP6 was measured in both the cell culture media and cell lysates. There was no genotype difference in intracellular BMP6 (Fig. 3a). However, H67D HFE macrophages secreted $112 \%$ more $(p<0.05)$ BMP6 compared to WT (Fig. 3b). There was no genotype difference between wildtype and H67D HFE macrophages in the expression of the BMP6 receptor ALK3 (Fig. 3c).

Iron release from macrophages is mediated by apotransferrin and DFO

Iron release was measured by loading the macrophages with radioactive iron, ${ }^{59} \mathrm{Fe}$, overnight. While no differences in genotype were observed in iron release in the control untreated groups, strikingly, both apo-transferrin and DFO promoted a release of iron previously not observed in macrophages, and in contrast to other cells, this release was not inhibited by hepcidin. Significant changes between the treatment groups were observed, beginning at hour 4 (data not shown). The most significant differences occurred at $24 \mathrm{~h}$ (Fig. 4).

H67D regulates migration, phagocytosis, and cytokine expression in macrophages

To characterize the functional consequences of H67D HFE mutation in macrophages, we assessed several major functions of macrophages; specifically, migration, phagocytosis, and expression of cytokines. To determine whether the H67D HFE genotype affects cellular migration, a chemotaxis assay was performed with FBS as the chemoattractant. Significantly more WT macrophages migrated than H67D HFE macrophages (Fig. 5). The H67D HFE macrophages also had approximately twice 

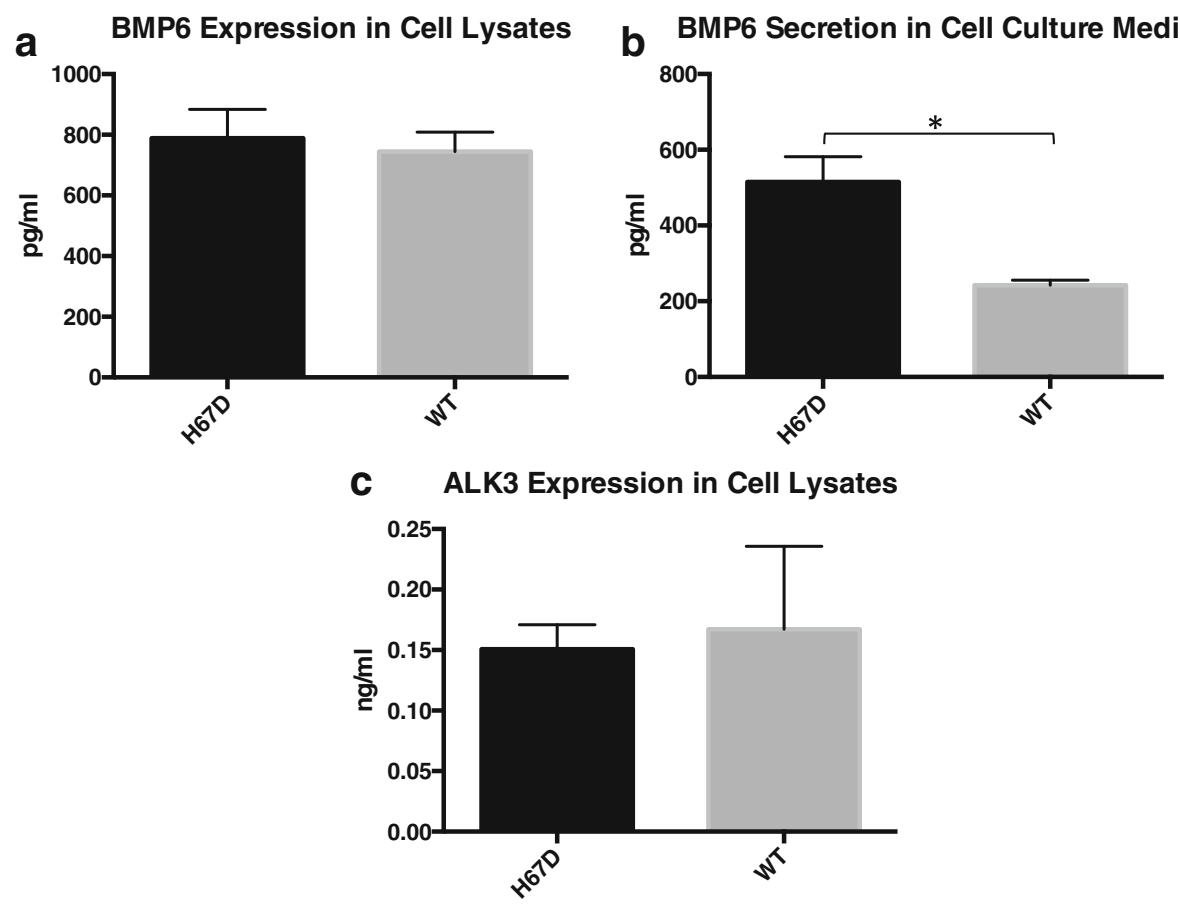

Fig. 3 Genotype Effects on BMP6 and its ALK3. Macrophages were plated in 100-mm² tissue culture dishes $\left(8 \times 10^{6}\right.$ cells/dish). Following differentiation, the cell culture media was replaced with fresh control media for $24 \mathrm{~h}$. After $24 \mathrm{~h}$, the media was collected and cells were harvested and lysed for analysis by ELISA. BMP6 expression was measured in the cell lysates (a) and secretion in the cell culture media (b). ALK3 expression was determined in the cell lysates (c). Absorbance was measured on a SpectraMax 340PC plate reader. Data represent the mean \pm SEM from three independent experiments performed each time in triplicate. Statistical significance was measured using an unpaired $t$ test with Welch's correction. ${ }^{*} p<0.05$

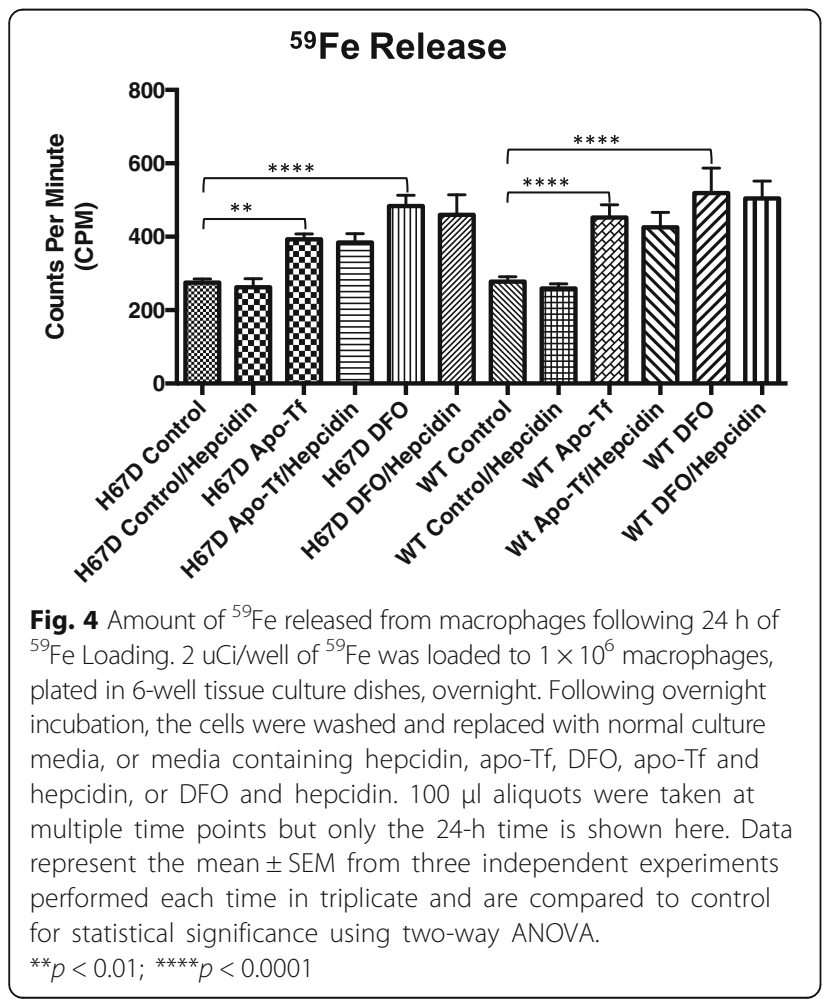

the amount of phagocytic activity $(p<0.0001)$ compared to the wildtype macrophages (Fig. 6).

To determine whether H67D HFE alters cytokine expression, 40 different cytokines were analyzed using a cytokine array panel on macrophages under 3 different conditions; control, $50 \mathrm{ng} / \mathrm{ml}$ LPS or $100 \mu \mathrm{M}$ paraquat. Of the 40 cytokines analyzed, 15 were detected within the macrophage cell lysates and six (M-CSF, TREM-1, SICAM-1, JE, IL1ra, and MIP2) showed significant differences between genotypes. M-CSF was the only cytokine that showed a significant genotype difference in the cells incubated with control media only (Table 1). The remaining five cytokines had significant genotype differences following exposure of the macrophages to LPS. Cytokines, TREM-1 and SICAM-1, were significantly increased within wildtype macrophages; whereas JE, IL-1ra, and MIP-2 were significantly increased in H67D HFE macrophages (Table 1). Exposure of macrophages to paraquat did not induce any significant differences between the genotypes (data not shown).

\section{Discussion}

This study was undertaken because of the role macrophages and microglia play in the engagement of inflammatory responses that impact repair of tissue damage and outcome of disease [17-20]. The H63D variant of 

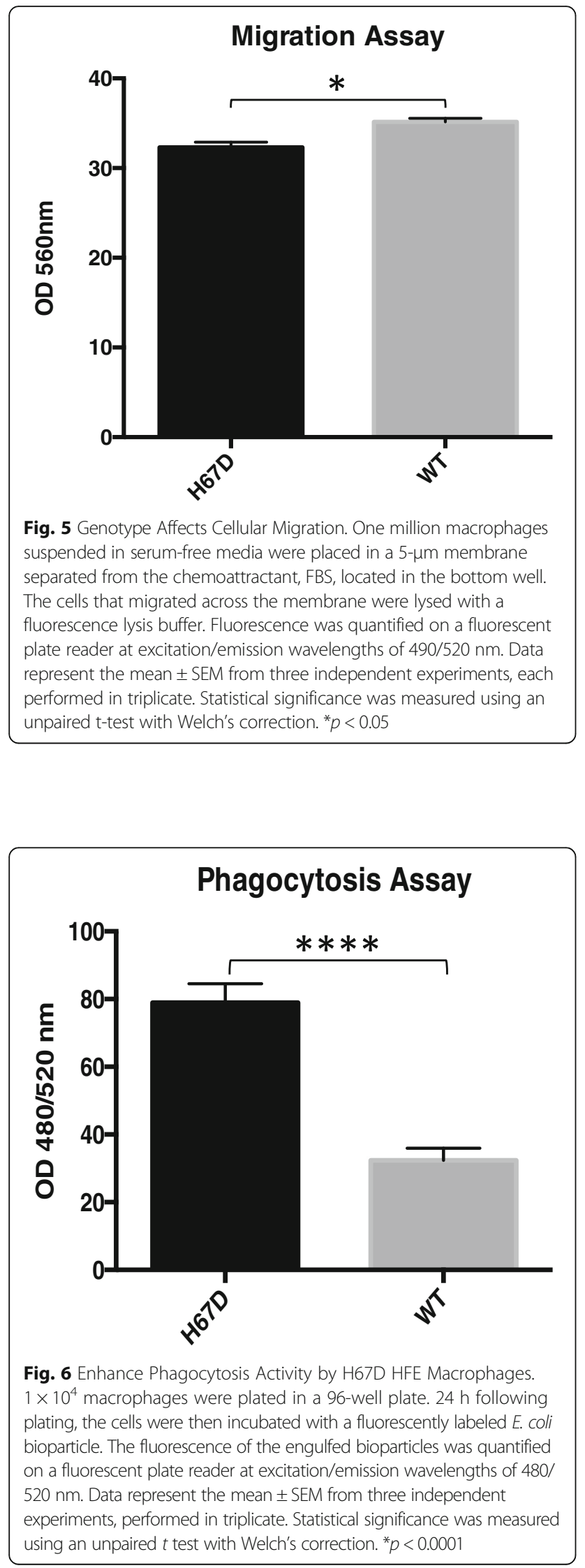

Table 1 Cytokine expression panel comparing H67D HFE and WT macrophages

\begin{tabular}{|c|c|c|}
\hline Cytokines & $\begin{array}{l}\text { Control media treatment } \\
\text { H67D vs. WT }\end{array}$ & $\begin{array}{l}\text { LPS media treatment } \\
\text { H67D vs. WT }\end{array}$ \\
\hline SICAM-1 & 0.97-Fold & $0.76-$ Fold ${ }^{* * *}$ \\
\hline IL-1a & 0.89-Fold & 0.66-Fold \\
\hline $\mathrm{IL}-1 \beta$ & 1.21-Fold & 0.97-Fold \\
\hline IL-1ra & 1.26-Fold & 1.27-Fold* \\
\hline IL-10 & 1.82-Fold & 1.09-Fold \\
\hline IL-16 & 1.18-Fold & 0.77-Fold \\
\hline IL-17 & 1.55-Fold & 1.44-Fold \\
\hline IL-23 & nd & 0.48-Fold \\
\hline KC & 0.76-Fold & 1.65-Fold \\
\hline M-CSF & 0.77 -Fold ${ }^{* *}$ & 0.90-Fold \\
\hline JE & 1.01-Fold & 1.51-Fold**** \\
\hline MIP-2 & 0.38-Fold & $1.76-F o l d * * * *$ \\
\hline RANTES & 1.35-Fold & 0.95-Fold \\
\hline TNF- $a$ & 1.41-Fold & 1.2-Fold \\
\hline TREM-1 & 0.95-Fold & 0.6-Fold* \\
\hline
\end{tabular}

Cell lysates from macrophages conditioned with control media or $50 \mathrm{ng} / \mathrm{ml}$ LPS were analyzed on a nitrocellulose membrane containing 40 different cytokines. The membranes were exposed using GE Amersham Imager 600. Of the 40 cytokines, 15 cytokines (represented in the table) had measurable levels of expression in at least one condition. Five of the 15 had genotype-specific responses to LPS and only one had differences in the non-LPS stimulated cells. Data are reported as fold change of H67D macrophages compared to WT. Statistical significance was measured using a one-way ANOVA. ${ }^{*} p<0.05$, ${ }^{* *} p<0.01$, ${ }^{* * *} p<0.001$. ${ }^{* * *} p<0.0001$

the HFE gene is reportedly a disease modifier for a number of neurodegenerative diseases and possibly cancer [7, 45]. In this study, we demonstrate that the H67D HFE genotype impacts a number of critical macrophage functions, such as cytokine profiles, migration and phagocytosis. There were minimal differences in iron handling between the genotypes; however, the significantly greater increase in L-ferritin in the H67D HFE cells following iron exposure indicates a fundamental difference in storing of iron between the genotypes. The differences in BMP6 secretion between the two genotypes could impact iron handling in the body. The HFE protein reportedly upregulates hepcidin levels through the BMP6 pathway [46]. Hepcidin is a major iron regulatory protein and an increase in hepcidin production could result in decreased iron uptake from the gut [47]. The expectation would be that increased hepcidin would decrease the release of iron from the macrophages [48] but in this study, hepcidin did not block the release of iron that was induced by apo-Tf or exposure to iron chelation. The release of iron from macrophages upon exposure to apo-Tf (iron-poor transferrin) can increase the release of iron from macrophages is a significant and novel finding. 
HFE genotype impacted fundamental functions of macrophages such as proliferation and survival. WT macrophages, but not H67D HFE macrophages, treated with iron had a significant increase in cellular proliferation. Iron is critical for cell proliferation, including macrophages $[49,50]$. The mechanism underlying the differences in proliferation response in the absence of other stimulatory factors is not known but indicates fundamental differences in iron handling. In support of this idea, macrophages of both genotypes loaded iron as indicated by a similar percentage increase in L-ferritin, but the final concentration in L-ferritin was twice the amount in the H67D HFE macrophages compared to wildtype suggesting more iron was stored rather than made bioavailable. An increase in L-ferritin-positive microglia was also reported in the brain in mice carrying the H67D HFE genotype [13]. The iron export protein ferroportin $[49,50]$ also increased with iron loading as expected [51]: however, the increase was not genotype specific. These data suggest that regulation of iron export was similar between the two genotypes, a notion supported by the iron release experiments. There were no differences between genotype or treatment groups in the levels of iron import protein, transferrin receptor (TfR) (Fig. 2d). The regulation of ferroportin, ferritin, and transferrin receptor are mediated through iron regulatory element/iron regulatory protein system (IRE/IRP) $[52,53]$. This post-transcriptional regulation typically results in complimentary expression of proteins, in response to iron changes. Thus, the lack of a predictable response in IRE/IRP-regulated protein expression in macrophages is an area for additional investigation.

A significant function of macrophages is recycling of iron [54]. The secretion of iron from macrophages is mediated by both ferroportin [55] and $\mathrm{H}$-ferritin [56]. However, the regulation of iron secretion is unclear. We demonstrated that iron release is signaled by the presence of apo-Tf and DFO. This finding suggests that circulating transferrin in the serum, which is $70 \%$ unsaturated [57], can serve as a mechanism to induce the release of iron from macrophages. We previously reported that apo-Tf can induce iron release from endothelial cells of the blood-brain-barrier (BBB); therefore, the function of apo-Tf to remove iron from cells may be a significant and unrecognized function of this protein [58]. Moreover, the response by the macrophages to release iron when exposed to DFO suggests treatment with iron chelators in clinical settings may also remove iron from macrophages. We attempted to block the release of iron by using hepcidin. Hepcidin binds to ferroportin and limits iron release in a number of cells [59]. The presence of hepcidin in the media did not limit the iron release by DFO or apo-Tf, consistent with other reports of an export system independent of the hepcidin and ferroportin system [60].

Hepcidin secretion is regulated by stimulation of BMP6 through its receptor ALK3 [46]. The cellular levels of BMP6 and ALK3 were not affected by genotype but secreted BMP6 was elevated in the H67D HFE cells. The combination of normal levels in the cell plus increased expression of BMP6 suggests an increased synthesis of this protein in the H67D cells. Higher levels of secreted BMP6 could result in more stimulation of ALK3 receptors on hepatocytes and translate to higher levels of circulating hepcidin. However, increased circulating hepcidin may not limit the iron release from macrophages as indicated in our study and others [60]. In contrast, however, hepcidin production is reduced by IL-1 receptor antagonist (IL-1ra), which was elevated in the H67D HFE macrophages compared to WT. These results indicate a complex signaling system via cytokines for hepcidin production that is genotype dependent.

By secreting cytokines, macrophages play a key role as inflammatory cells and are critical in the innate immune response. HFE knock out mice have an attenuated immune response [61]. The decrease in expression of cytokines, TREM-1 and sICAM1 by the H67D HFE macrophages would be consistent with a decreased inflammatory response and can lead to disease promotion. For example, decreased expression of TREM-1 in microglia has been correlated with decreased clearance of $A \beta$ plaques in models of Alzheimer's disease [62]. Furthermore, increased expression of SICAM-1 has been found to decrease the formation of $A \beta$ plaques through microglia secretion of neprilysin, the $A \beta$-degrading enzyme [63]. These studies further support the contribution of H67D HFE mutation in the progression of neurodegenerative disease.

As part of the immune response, macrophages migrate to different infection sites and engage in phagocytosis. The H67D HFE macrophages have increased phagocytic ability compared to WT (Fig. 6) but slower migration rates than wildtype macrophages (Fig. 5). We previously reported that increasing iron content in a rat microglial cell line was associated with a decrease in phagocytic activity following LPS stimulation [24]. Given the number of different conditions in our previous study, direct comparisons to the current study are difficult, but clearly, iron status impacts phagocytosis. Furthermore, two cytokines involved in chemotaxis, macrophage inflammatory protein 2 (MIP-2) and JE, were elevated in the H67D HFE macrophages. We also previously reported that monocyte chemoattractant protein-1 (MCP-1) is elevated in amyotrophic lateral sclerosis patients with H63D HFE [64], as well as in SH-SY5Y neuroblastoma cells transfected with the H63D HFE mutation [65]. Although we measured expression and 
not secretion, intracellular expression of cytokines has been found to correlate to cytokine secretion [66, 67]. These findings support the concept that the HFE mutation may promote increased migration of lymphocytes and microglia through the secretion of chemoattractant proteins.

\section{Conclusions}

In general, these results indicate that the H67D HFE genotype impacts macrophage phenotype. These studies identify areas for future studies into HFE impact via macrophage and microglia dysfunction, in the context of neurodegenerative disorders, such as Alzheimer's, ALS, and Parkinson's as well as many types of cancer.

\section{Abbreviations}

ALK3/BMPI: Bone morphogenetic protein type I receptor; ALS: Amyotrophic lateral sclerosis; ANOVA: Analysis of variance; Apo-Tf: Apo-Transferrin (iron poor transferrin); BBB: Blood-brain-barrier; BMM: Bone marrow macrophage; BMP: Bone morphogenetic protein; DFO: Deferoxamine; DMEM: Dulbecco's Modified Eagle's Medium; DPBS: Dulbecco's phosphate-buffered saline; ELISA: Enzyme-linked immunosorbent assay; FAC: Ferric ammonium citrate; FBS: Fetal bovine serum; II-1ra: Interleukin 1 receptor antagonist; IRE: Iron regulatory element; IRP: Iron regulatory protein; LDH: Lactate dehydrogenase; LPS: Lipopolysaccharide; MCP-1: Monocyte chemoattractant protein-1; MCSF: Macrophage-colony stimulating factor; MIP-2: Macrophage inflammatory protein-2; MTT: 3-(4,5-Dimethylthiazol-2-YI)-2,5-diphenyltetrazolium bromide; SEM: Standard error of mean; WT: Wildtype

\section{Acknowledgements}

Not applicable

\section{Funding}

Not applicable

\section{Availability of data and materials}

All data generated or analyzed during this study are included in this published article.

\section{Authors' contributions}

AMN, EN, IS, and JRC designed the research. AMN performed the experiments. AMN and JRC analyzed the experiments. AMN, EN, IS, and JRC contributed to the production of the manuscript. All authors read and approved the final manuscript.

\section{Ethics approval}

All procedures were approved by the Pennsylvania State University College of Medicine Institutional Animal Care and Use Committee, protocol 04-166.

\section{Consent for publication}

Not applicable

\section{Competing interests}

The authors declare that they have no competing interests.

\section{Publisher's Note}

Springer Nature remains neutral with regard to jurisdictional claims in published maps and institutional affiliations.

\section{Author details}

'Department of Neurosurgery, The Pennsylvania State University College of Medicine, M.S. Hershey Medical Center, Hershey, PA 17033, USA.

${ }^{2}$ Department of Neural and Behavior Science, The Pennsylvania State University College of Medicine, M.S. Hershey Medical Center, Hershey 17033, PA, USA.
Received: 16 June 2017 Accepted: 3 January 2018

Published online: 01 February 2018

\section{References}

1. Wang J, Pantopoulos K. Regulation of cellular iron metabolism. The Biochemical journal. 2011:434(3):365-81.

2. Feder JN, Gnirke A, Thomas W, Tsuchihashi Z, Ruddy DA, Basava A, Dormishian F, Domingo R, Ellis MC, Fullan A, et al. A novel MHC class I-like gene is mutated in patients with hereditary haemochromatosis. Nat Genet. 1996;13(4):399-408.

3. Lebrón JA, Bennett MJ, Vaughn DE, Chirino AJ, Snow PM, Mintier GA, Feder JN, Bjorkman PJ. Crystal structure of the Hemochromatosis protein HFE and characterization of its interaction with Transferrin receptor. Cell. 1998;93(1):111-23.

4. Bennett MJ, Lebron JA, Bjorkman PJ. Crystal structure of the hereditary haemochromatosis protein HFE complexed with transferrin receptor. Nature. 2000;403(6765):46-53.

5. Steinberg KK, Cogswell ME, Chang JC, Caudill SP, McQuillian GM, Bowman BA, Grummer-Strawn LM, Sampson EJ, Khoury MJ, Gallagher ML. Prevalence of C282Y and H63D mutations in the Hemochromatosis (HFE) gene in the United States. JAMA. 2001:285(17):2216-22.

6. Marshall DS, Linfert DR, Tsongalis GJ. Prevalence of the C282Y and H63D polymorphisms in a multi-ethnic control population. Int J Mol Med. 1999; 4(4):389-93

7. Nandar W, Connor JR. HFE gene variants affect iron in the brain. J Nutr. 2011;141(4):729S-39S.

8. Burt MJ, George PM, Upton JD, Collett JA, Frampton CMA, Chapman TM, Walmsley TA, Chapman BA. The significance of haemochromatosis gene mutations in the general population: implications for screening. Gut. 1998; 43(6):830-6.

9. Wang X-S, Lee S, Simmons Z, Boyer P, Scott K, Liu W, Connor J. Increased incidence of the Hfe mutation in amyotrophic lateral sclerosis and related cellular consequences. J Neurol Sci. 2004;227(1):27-33.

10. Goodall EF, Greenway MJ, van Marion I, Carroll CB, Hardiman O, Morrison KE. Association of the H63D polymorphism in the hemochromatosis gene with sporadic ALS. Neurology. 2005:65(6):934-7.

11. Moalem S, Percy ME, Andrews DF, Kruck TP, Wong S, Dalton AJ, Mehta P, Fedor B, Warren AC. Are hereditary hemochromatosis mutations involved in Alzheimer disease? Am J Med Genet. 2000;93(1):58-66.

12. Nandar W, Neely EB, Simmons Z, Connor JR. H63D HFE genotype accelerates disease progression in animal models of amyotrophic lateral sclerosis. Biochim Biophys Acta (BBA) - Mol Basis Dis. 2014;1842(12, Part A):2413-26.

13. Nandar W, Neely EB, Unger E, Connor JR. A mutation in the HFE gene is associated with altered brain iron profiles and increased oxidative stress in mice. Biochim Biophys Acta (BBA) - Mol Basis Dis. 2013;1832(6):729-41.

14. Ali-Rahmani F, Grigson PS, Lee S, Neely E, Connor JR, Schengrund CL. H63D mutation in hemochromatosis alters cholesterol metabolism and induces memory impairment. Neurobiol Aging. 2014;35(6):1511.e1511-2.

15. Valberg LS, Simon JB, Manley PN, Corbett WE, Ludwig J. Distribution of storage iron as body iron stores expand in patients with hemochromatosis. Transl Res. 86(3):479-89.

16. Brink B, Disler $P$, Lynch $S$, Jacobs $P$, Charlton $R$, Bothwell T. Patterns of iron storage in dietary iron overload and idiopathic hemochromatosis. J Lab Clin Med. 1976;88(5):725-31.

17. Zhou XY, Tomatsu S, Fleming RE, Parkkila S, Waheed A, Jiang J, Fei Y, Brunt EM, Ruddy DA, Prass CE, et al. HFE gene knockout produces mouse model of hereditary hemochromatosis. Proc Natl Acad Sci. 1998;95(5):2492-7.

18. Goodman GT, Koprowski H. Macrophages as a cellular expression of inherited natural resistance. Proc Natl Acad Sci U S A. 1962;48(2):160-5.

19. Mackaness GB. Cellular immunity and the parasite. Adv Exp Med Biol. 1977; 93:65-73.

20. Gratchev A, Guillot P, Hakiy N, Politz O, Orfanos CE, Schledzewski K, Goerdt S. Alternatively activated macrophages differentially express fibronectin and its splice variants and the extracellular matrix protein betalG-H3. Scand J Immunol. 2001;53(4):386-92.

21. Rosato-Siri MV, Marziali L, Guitart ME, Badaracco ME, Puntel M, Pitossi F, Correale J, Pasquini JM. Iron availability compromises not only Oligodendrocytes but also Astrocytes and Microglial cells. Mol Neurobiol. 2017; https://doi.org/10.1007/s12035-016-0369-2.

22. Rathnasamy G, Ling E-A, Kaur C. Iron and iron regulatory proteins in amoeboid Microglial cells are linked to Oligodendrocyte death in hypoxic neonatal rat Periventricular white matter through production of 
Proinflammatory cytokines and reactive oxygen/nitrogen species. J Neurosci. 2011;31(49):17982.

23. Zhang $X-Y$, Cao J-B, Zhang L-M, Li Y-F, Mi W-D. Deferoxamine attenuates lipopolysaccharide-induced neuroinflammation and memory impairment in mice. J Neuroinflammation. 2015;12:20.

24. Mairuae N, Connor JR, Cheepsunthorn P. Increased cellular iron levels affect matrix metalloproteinase expression and phagocytosis in activated microglia. Neurosci Lett. 2011;500(1):36-40.

25. Zhang X, Surguladze N, Slagle-Webb B, Cozzi A, Connor JR. Cellular iron status influences the functional relationship between microglia and oligodendrocytes. Glia. 2006;54(8):795-804.

26. Montosi G, Paglia P, Garuti C, Guzman CA, Bastin JM, Colombo MP, Pietrangelo A. Wild-type HFE protein normalizes transferrin iron accumulation in macrophages from subjects with hereditary hemochromatosis. Blood. 2000;96(3):1125-9.

27. Drakesmith H, Sweetland E, Schimanski L, Edwards J, Cowley D, Ashraf M, Bastin J, Townsend ARM. The hemochromatosis protein HFE inhibits iron export from macrophages. Proc Natl Acad Sci. 2002;99(24):15602-7.

28. Lull ME, Block ML. Microglial activation \& chronic Neurodegeneration. Neurotherapeutics: the journal of the American Society for Experimental NeuroTherapeutics. 2010;7(4):354-65.

29. Andersen HH, Johnsen KB, Moos T. Iron deposits in the chronically inflamed central nervous system and contributes to neurodegeneration. Cell Mol Life Sci. 2014;71(9):1607-22.

30. Berg D, Gerlach M, Youdim MBH, Double KL, Zecca L, Riederer P, Becker G. Brain iron pathways and their relevance to Parkinson's disease. $J$ Neurochem. 2001;79(2):225-36.

31. Gorter JA, Mesquita ARM, Van Vliet EA, Da Silva FHL, Aronica E. Increased expression of Ferritin, an iron-storage protein, in specific regions of the Parahippocampal cortex of epileptic rats. Epilepsia. 2005;46(9):1371-9.

32. London A, Cohen M, Schwartz M. Microglia and monocyte-derived macrophages: functionally distinct populations that act in concert in CNS plasticity and repair. Front Cell Neurosci. 2013;7:34.

33. Simard AR, Soulet D, Gowing G, Julien JP, Rivest S. Bone marrow-derived microglia play a critical role in restricting senile plaque formation in Alzheimer's disease. Neuron. 2006;49(4):489-502.

34. Goldstein EZ, Church JS, Pukos N, Gottipati MK, Popovich PG, McTigue DM. Intraspinal TLR4 activation promotes iron storage but does not protect neurons or oligodendrocytes from progressive iron-mediated damage. Exp Neurol. 2017;298(Part A):42-56.

35. Luo C, Jian C, Liao Y, Huang Q, Wu Y, Liu X, Zou D, Wu Y. The role of microglia in multiple sclerosis. Neuropsychiatr Dis Treat. 2017;13:1661-7.

36. Hambardzumyan D, Gutmann DH, Kettenmann $\mathrm{H}$. The role of microglia and macrophages in glioma maintenance and progression. Nat Neurosci. 2016;19(1):20-7.

37. Martinez di Montemuros F, Tavazzi D, Salsano E, Piepoli T, Pollo B, Fiorelli G, Finocchiaro G. High frequency of the H63D mutation of the hemochromatosis gene (HFE) in malignant gliomas. Neurology. 2001;57(7):1342.

38. Gunel-Ozcan A, Alyllmaz-Bekmez S, Guler EN, Guc D. HFE H63D mutation frequency shows an increase in Turkish women with breast cancer. BMC Cancer. 2006;6:37.

39. Gharib AF, Karam RA, Pasha HF, Radwan MI, Elsawy WH. Polymorphisms of hemochromatosis, and alpha-1 antitrypsin genes in Egyptian HCV patients with and without hepatocellular carcinoma. Gene. 2011;489(2):98-102.

40. Tomatsu S, Orii KO, Fleming RE, Holden CC, Waheed A, Britton RS, Gutierrez MA, Velez-Castrillon S, Bacon BR, Sly WS. Contribution of the H63D mutation in HFE to murine hereditary hemochromatosis. Proc Natl Acad Sci. 2003;100(26):15788-93.

41. Zhang X, Goncalves R, Mosser DM: The isolation and characterization of Murine macrophages. Current protocols in immunology / edited by John $\mathrm{E}$ Coligan [et al] 2008, CHAPTER:Unit-14.11.

42. Cooper PH, Mayer P, Baggiolini M. Stimulation of phagocytosis in bone marrow-derived mouse macrophages by bacterial lipopolysaccharide: correlation with biochemical and functional parameters. Journal of immunology (Baltimore, Md : 1950). 1984;133(2):913-22.

43. Day BJ, Patel M, Calavetta L, Chang L-Y, Stamler JS. A mechanism of paraquat toxicity involving nitric oxide synthase. Proc Natl Acad Sci U S A. 1999;96(22):12760-5

44. Bali PK, Zak O, Aisen P. A new role for the transferrin receptor in the release of iron from transferrin. Biochemistry. 1991;30(2):324-8.

45. Weston C, Connor J. Evidence for the influence of the iron regulatory MHC class I molecule HFE on tumor progression in experimental models and clinical populations. Translational Oncogenomics. 2014;6:1-12.
46. Wu X-g, Wang Y, Wu Q, Cheng W-H, Liu W, Zhao Y, Mayeur C, Schmidt PJ, PB Y, Wang F, et al. HFE interacts with the BMP type I receptor ALK3 to regulate hepcidin expression. Blood. 2014;124(8):1335-43.

47. Nicolas G, Bennoun M, Devaux I, Beaumont C, Grandchamp B, Kahn A, Vaulont $\mathrm{S}$. Lack of hepcidin gene expression and severe tissue iron overload in upstream stimulatory factor 2 (USF2) knockout mice. Proc Natl Acad Sci U S A. 2001;98(15):8780-5.

48. Schmidt PJ. Regulation of iron metabolism by Hepcidin under conditions of inflammation. J Biol Chem. 2015;290(31):18975-83.

49. Pourcelot E, Lenon M, Mobilia N, Cahn JY, Arnaud J, Fanchon E, Moulis JM, Mossuz P. Iron for proliferation of cell lines and hematopoietic progenitors: nailing down the intracellular functional iron concentration. Biochim Biophys Acta. 2015;1853(7):1596-605

50. Oria R, Alvarez-Hernández X, Licéaga J, Brock JH. Uptake and handling of iron from transferrin, lactoferrin and immune complexes by a macrophage cell line. Biochem J. 1988;252(1):221-5.

51. Knutson MD, Vafa MR, Haile DJ, Wessling-Resnick M. Iron loading and erythrophagocytosis increase ferroportin 1 (FPN1) expression in $\mathrm{J774}$ macrophages. Blood. 2003;102(12):4191-7.

52. Hentze MW, Caughman SW, Rouault TA, Barriocanal JG, Dancis A, Harford JB, Klausner RD. Identification of the iron-responsive element for the translational regulation of human Ferritin mRNA. Science. 1987; 238(4833):1570-3.

53. Hentze MW, Caughman SW, Casey JL, Kodier DM, Rouault TA, Harford JB, Klausner RD. A model for the structure and functions of iron-responsive elements. Gene. 1988;72(1-2):201-8.

54. Ganz T. Macrophages and iron metabolism. Microbiology spectrum. 2016; 4(5):MCHD-0037-2016.

55. Delaby C, Pilard N, Puy H, Canonne-Hergaux F. Sequential regulation of ferroportin expression after erythrophagocytosis in murine macrophages: early mRNA induction by haem, followed by iron-dependent protein expression. Biochem J. 2008;411(1):123.

56. Cohen LA, Gutierrez L, Weiss A, Leichtmann-Bardoogo Y, Zhang D-I, Crooks $D R$, Sougrat R, Morgenstern A, Galy B, Hentze MW, et al. Serum ferritin is derived primarily from macrophages through a nonclassical secretory pathway. Blood. 2010;116(9):1574-84.

57. Luck AN, Mason AB. Transferrin-mediated cellular iron delivery. Curr Top Membr. 2012;69:3-35.

58. Simpson IA, Ponnuru P, Klinger ME, Myers RL, Devraj K, Coe CL, Lubach GR, Carruthers A, Connor JR. A novel model for brain iron uptake: introducing the concept of regulation. Journal of cerebral blood flow and metabolism : official journal of the International Society of Cerebral Blood Flow and Metabolism. 2015;35(1):48-57.

59. Nemeth E, Tuttle MS, Powelson J, Vaughn MB, Donovan A, Ward DM, Ganz T, Kaplan J. Hepcidin regulates cellular iron efflux by binding to Ferroportin and inducing its internalization. Science. 2004;306(5704):2090-3.

60. Willemetz A, Beatty S, Richer E, Rubio A, Auriac A, Milkereit RJ, Thibaudeau O, Vaulont S, Malo D, Canonne-Hergaux F. Iron- and Hepcidin-independent Downregulation of the iron exporter Ferroportin in macrophages during salmonella infection. Front Immunol. 2017:8:498.

61. Wang L, Johnson EE, Shi HN, Allan Walker W, Wessling-Resnick M, Cherayil BJ. Attenuated inflammatory responses in hemochromatosis reveal a role for iron in the regulation of macrophage cytokine translation. Journal of immunology (Baltimore, Md : 1950). 2008;181(4): 2723-31.

62. Jiang T, Zhang YD, Gao Q, Zhou JS, Zhu XC, Lu H, Shi JQ, Tan L, Chen Q, JT Y. TREM1 facilitates microglial phagocytosis of amyloid beta. Acta Neuropathol. 2016;132(5):667-83.

63. Kim JY, Kim DH, Kim JH, Lee D, Jeon HB, Kwon SJ, Kim SM, Yoo YJ, Lee EH, Choi SJ, et al. Soluble intracellular adhesion molecule-1 secreted by human umbilical cord blood-derived mesenchymal stem cell reduces amyloid-beta plaques. Cell Death Differ. 2012;19(4):680-91.

64. Mitchell RM, Simmons Z, Beard JL, Stephens HE, Connor JR. Plasma biomarkers associated with ALS and their relationship to iron homeostasis. Muscle Nerve. 2010;42(1):95-103.

65. Mitchell RM, Lee SY, Randazzo WT, Simmons Z, Connor JR: Influence of HFE variants and cellular iron on monocyte chemoattractant protein-1. J Neuroinflammation 2009, 6:6.

66. Shooshtari P, Fortuno ES, Blimkie D, Yu M, Gupta A, Kollmann TR, Brinkman RR. Correlation analysis of intracellular and secreted cytokines 
via the generalized integrated mean fluorescence intensity (GiMFI).

Cytometry Part A : the journal of the International Society for Analytical Cytology. 2010;77(9):873-80.

67. Schuerwegh AJ, De Clerck LS, Bridts CH, Stevens WJ. Comparison of

intracellular cytokine production with extracellular cytokine levels using two flow cytometric techniques. Cytometry B Clin Cytom. 2003;55(1):52-8.

Submit your next manuscript to BioMed Central and we will help you at every step:

- We accept pre-submission inquiries

- Our selector tool helps you to find the most relevant journal

- We provide round the clock customer support

- Convenient online submission

- Thorough peer review

- Inclusion in PubMed and all major indexing services

- Maximum visibility for your research

Submit your manuscript at www.biomedcentral.com/submit 